\title{
Erratum to: 3D Printed Modeling of the Mitral Valve for Catheter-Based Structural Interventions
}

\author{
Marija Vukicevic, ${ }^{1}$ Daniel S. Puperi, ${ }^{2}$ K. Jane Grande-Allen, ${ }^{2}$ and Stephen H. Little ${ }^{1}$ \\ ${ }^{1}$ Department of Cardiology, Houston Methodist Research Institute, Weill Cornell Medicine/Houston Methodist Hospital, 6550 \\ Fannin Street, SM-677, Houston, TX 77030, USA; and ${ }^{2}$ Department of Bioengineering, Rice University, 6100 Main St., MS 142, \\ Houston, TX 77005, USA
}

\section{Erratum to: Annals of Biomedical Engineering DOI 10.1007/s10439-016-1676-5}

Daniel S. Puperi's name was misspelled in the original publication of this article. It has since been corrected.

Address correspondence to Stephen H. Little, Department of Cardiology, Houston Methodist Research Institute, Weill Cornell Medicine/Houston Methodist Hospital, 6550 Fannin Street, SM-677, Houston, TX 77030, USA. Electronic mail: shlittle@houstonmethodist. org

The online version of the original article can be found under doi: 10.1007/s10439-016-1676-5. 